\title{
Can minimally invasive puncture and drainage for hypertensive spontaneous Basal Ganglia intracerebral hemorrhage improve patient outcome: a prospective non-randomized comparative study
}

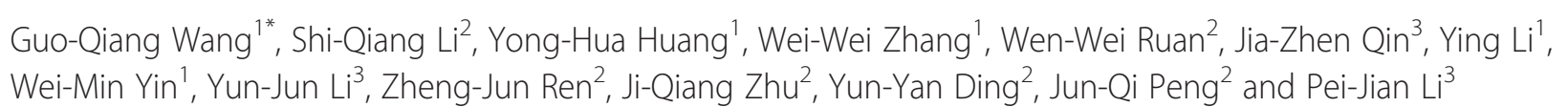

\begin{abstract}
Background: The treatment of hypertensive spontaneous intracranial hemorrhage (ICH) is still controversial. The purpose of the present study was to investigate whether minimally invasive puncture and drainage (MIPD) could improve patient outcome compared with decompressive craniectomy (DC).

Methods: Consecutive patients with ICH ( $\geqq 30 \mathrm{~mL}$ in basal ganglia within 24 hours of ictus) were non-randomly assigned to receive MIPD (group A) or DC (group B) hematoma evacuation. The primary outcome was death at 30 days after onset. Functional independence was assessed at 1 year using the Glasgow Outcome Scale.
\end{abstract}

Results: A total of 198 patients met the per protocol analysis (84 in group A and 114 in group B). The initial Glasgow Coma Scale (GCS) score was $8.1 \pm 3.4$ and the National Institutes of Health Stroke Scale (NIHSS) score was $20.8 \pm 5.3$. The mean hematoma volume (HV) was $56.7 \pm 23.0 \mathrm{~mL}$, and there was extended intraventricular hemorrhage (IVH) in 134 patients. There were no significant intergroup differences in the above baseline data, except group A had a higher mean age than that of group $B(59.4 \pm 14.5$ vs. $55.3 \pm 11.1$ years, $P=0.025)$.

The cumulative mortalities at 30 days and 1 year were $32.3 \%$ and $43.4 \%$, respectively, and there were no significant differences between groups A and B. However, the mortality for patients $\leqq 60$ years, NIHSS $<15$ or HV $\leqq 60 \mathrm{~mL}$ was significantly lower in group $A$ than that in group $B(a l l P<0.05)$. The cumulative functional independence at 1 year was $26.8 \%$, and the difference between group $A(33 / 84,39.3 \%)$ and group $B(20 / 114,17.5 \%)$ was significant $(P=0.001)$. Multivariate logistic regression analysis showed that a favorable outcome after 1 year was associated with the difference in therapies, age, GCS, HV, IVH and pulmonary infection (all $P<0.05$ ).

Conclusions: For patients with hypertensive spontaneous ICH (HV $\geqq 30 \mathrm{~mL}$ in basal ganglia), MIPD may be a more effective treatment than DC, as assessed by a higher rate of functional independence at 1 year after onset as well as reduced mortality in patients $\leqq 60$ years of age, NIHSS $<15$ or $\mathrm{HV} \leqq 60 \mathrm{~mL}$.

Keywords: Intracerebral hemorrhage, Intraventricular hemorrhage, Minimal invasive puncture, Decompressive craniectomy, Recombinant tissue plasminogen activator, Urokinase

\footnotetext{
* Correspondence: wgqbj@163.com

'Department of Neurology, General Hospital of Beijing Command, Beijing

100700, China

Full list of author information is available at the end of the article
}

C Biomed Central (c) 2014 Wang et al.; licensee BioMed Central Ltd. This is an Open Access article distributed under the terms of the Creative Commons Attribution License (http://creativecommons.org/licenses/by/4.0), which permits unrestricted use, distribution, and reproduction in any medium, provided the original work is properly credited. The Creative Commons Public Domain Dedication waiver (http://creativecommons.org/publicdomain/zero/1.0/) applies to the data made available in this article, unless otherwise stated. 


\section{Background}

Hypertensive intracranial hemorrhage (ICH) in the area of the basal ganglia accounts for $50-70 \%$ of all spontaneous $\mathrm{ICH}$, and mortality at 30 days after onset is $33.3 \%$ to $50.6 \%$, $[1,2]$ while $41 \%$ of survivors has some degree of disability [3]. Hemostasis and clot removal achieved pathophysiologic benefits, including the prevention of hemorrhagic expansion, reduction of intracranial pressure and clot mass effect [4]. However, the optimal treatment choice for ICH, medical or surgical, continues to be controversial.

The largest prospective randomized study, the STICH trial [5], with 1033 patients from 107 centers over an 8-year period, indicated that surgical evacuation did not appear to be helpful in treating supratentorial ICH. The STICH II trial [6] was recently completed using including 601 conscious patients with superficial lobar intracerebral hemorrhages $(10-100 \mathrm{~mL})$ and without intraventricular hemorrhage, who received either early surgery or conservative treatment in a ratio of 1:1. This trial showed no significant outcome differences at 6 moths between the two groups.

Surgical hematoma evacuation failed to demonstrate a benefit to survival or morbidity, which may be attributable to some additional damage incurred to uninjured brain overlying the hematoma caused by the surgical approach. To minimize this risk, minimally invasive surgical strategies have been used.

A randomized controlled study by Miller et al. [7] investigated 10 patients with ICH who received endoscopic aspiration or a conservative treatment and found lower 6 month mortality in the endoscopic group than the medical group. However, the efficacy in this very small trial was limited to superficial lobe hematomas. Nishihara et al. [8] found that endoscopic evacuation provided better neurological outcomes than CT-guided stereotactic hematoma removal. However, among their 27 cases in the endoscopic group, more than $50 \%$ of the 15 patients with a good outcome had a small subcortical or cerebellar hemorrhage. The general outcomes of endoscopic and conservative treatments for basal ganglia hemorrhages have been shown to have no significant difference between them [9]. Thus, there is insufficient evidence to confirm that these treatments can improve functional outcomes of $\mathrm{ICH}$.

The optimal approach to remove a hematoma resulting from ICH would be a rapid, simple method that combines a high success rate with low risk and minimal cost. One technique that may have such characteristics is minimally invasive puncture and drainage (MIPD). MIPD is widely used in China; however, few studies have compared the efficacy of MIPD and DC for patients with hemorrhages of $30 \mathrm{~mL}$ or more in the basal ganglia. The present study was designed to investigate whether MIPD could improve outcomes in these patients compared with the traditional decompressive craniectomy (DC).

\section{Methods}

\section{Inclusion criteria}

Patients were eligible for the study if they had a hypertensive spontaneous $\mathrm{ICH}$ in the basal ganglia with a hematoma volume $(\mathrm{HV}) \geqq 30 \mathrm{~mL}$, the hematoma evacuation could start within 24 hours of ictus (if the onset was unobserved, it was considered to be at the last time the patient was definitely normal), and the informed consent for the operation could be obtained from patient's relative or guardian.

\section{Exclusion criteria}

Patients with ICH located in the cerebral lobes, infratentorial or subarachnoid areas of the brain; ICH caused by trauma, aneurysms, arteriovenous malformation; $\mathrm{ICH}$ secondary to an ischemic infarction or coagulopathy; or patients with previous neurological defects or without definite hypertension were excluded.

\section{Patients}

Consecutive patients with hypertensive spontaneous $\mathrm{ICH}$ were non-randomly admitted to General Hospital of the Beijing Military Region and Xianghe Hospital from February 2009 to February 2012. The study was approved by the Ethics Committee of General Hospital of Beijing Military Region.

\section{Grouping}

Patients who presented to the General Hospital of the Beijing Military Region were non-randomly admitted by an emergency neurologist to the neurology department to receive MIPD (group A) or to the neurosurgery department to undergo DC (group B) hematoma evacuation. Patients presented to the Xianghe hospital were admitted to its neurology department to receive MIPD. The final assignment of the group for each patient was determined by the patient's relative, who was presented with the risks and benefits of each $\mathrm{ICH}$ treatment from the neurologist: DC (general anesthesia, craniectomy, thorough hematoma evacuation under direct vision), MIPD (local anesthesia, minimal invasion, non direct vision, continuous drainage) or conservative medical treatment. All MIPD procedures in both hospitals were performed by the first author.

\section{Baseline index definition and classification}

Hypertension was judged to be present if the patient fulfilled one of the following criteria: (1) treatment with antihypertensive drugs, previously or currently; (2) repeated measurements of systolic blood pressure $>160 \mathrm{mmHg}$ or diastolic blood pressure $>95 \mathrm{mmHg}$ after admission. Diabetes mellitus (DM) was assessed if the patient had a history of DM or was taking anti-DM medications.

The scores from the Glasgow Coma Scale (GCS) were classified into 3 categories: mild (15-13), moderate (12-7) 
and severe (6-3). Scores from the National Institutes of Health Stroke Scale (NIHSS) were similarly classified: mild $(<15)$, moderate $(15-20)$ and severe $(>20)$.

$\mathrm{ICH}$ was diagnosed using a CT scan, with the hematoma located in the basal ganglia (internal and/or external capsule, caudate nucleus, thalamus, putamen, or more than one of the above structures). HV was calculated from the CT using the formula $A B C / 2,[10]$ where " $\mathrm{A}$ " and " $\mathrm{B}$ " represent the length and width diameters, respectively, of the largest hemorrhage slice, and "C" is the slice thickness, in centimeters. We classified HV into 2 categories: $\leqq 60 \mathrm{~mL}$ and $>60 \mathrm{~mL}$. The degree of an extended intraventricular hemorrhage (IVH) was classified into 4 categories, using the methods described by Graeb [11]: $0,1-4,5-8$ and 9-12 (from none to severe).

Time from onset to operation and complications, including rebleed (RB), renal failure (RF), pulmonary infection (PI) and upper gastrointestinal bleed (UGB) were also recorded.

\section{Interventions}

\section{Basal treatment}

All patients received basal medical management, including treatments for the control of cerebral edema, blood pressure and glycemia; gastric cytoprotection; nutritional support; and the prevention of complications.

\section{$D C$}

Patients in group B received DC. After approximately $10 * 10 \mathrm{~cm}^{2}$ temporoparietal craniectomy, the dura was opened in a cruciate manner; the hematoma was removed microscopically with a suction device through the middle temporal gyrus. Active bleeding was controlled with standard neurosurgical techniques. An external ventricular drain tube was set into the lateral ventricle for drainage, if IVH was present. The scalp was then closed.

\section{MIPD}

Patients in group A underwent MIPD as follows: 1) The body surface puncture site of the hematoma was determined based on the maximum hematoma slice on the CT film (Figure 1), avoiding major vessels and important functional areas. 2) A YL-I puncture needle (Beijing WanTeFu Medical Apparatus Co., Ltd. http://www.bjwtf. com/en) was used; the length $(\mathrm{mm})$ of the selected needle matched with the depth from the temporal scalp to the hematoma center. 3) After local anesthesia, the needle was drilled into the center of the hematoma via the surface localization puncture point, perpendicularly to the sagittal plane. 4) The drill bit of the needle was removed and a drainage tube was connected to the side hole of the needle. A 5-mL syringe was connected to the other end of the tube, and uncoagulated blood was gently aspirated. 5) The hematoma cavity was rinsed with saline through an ancillary washing needle. 6) Urokinase (10000 U)/saline $(3 \mathrm{~mL})$ was infused into the clot, which was bathed for 1 hour and then drained into a closed collection bag. 7) A follow-up CT scan was obtained 12-24 hours after MIPD. Step 6 was repeated if residual blood remained, until the hemorrhage was completely removed or until the remaining $\mathrm{HV}$ was less than $10 \mathrm{~mL}(2-7$ days were generally required). Subsequently, the puncture needle was removed and the puncture site was bandaged for 5-7 days. If severe IVH was present, lateral ventricular external drainage was performed just after step 6 .

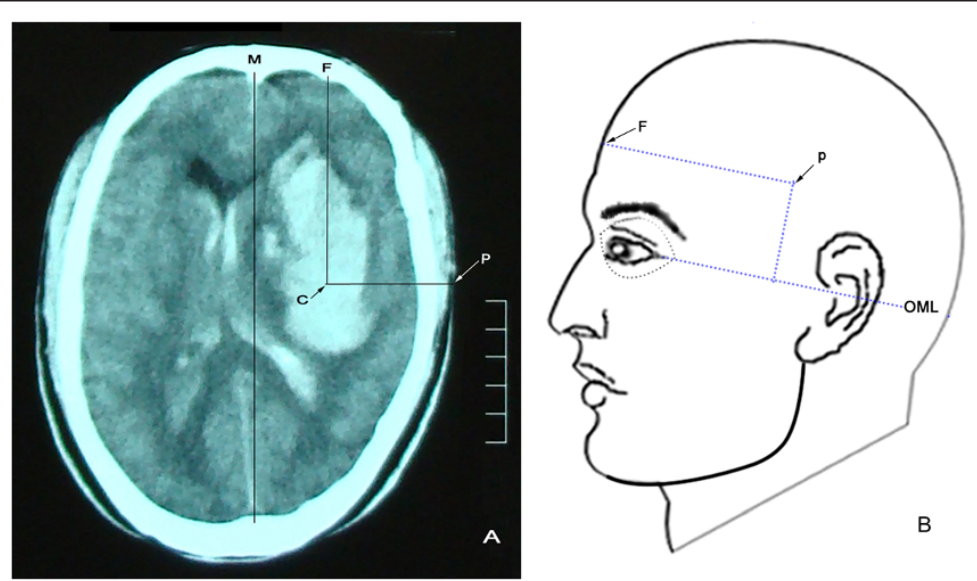

Figure 1 Brain CT scan slice with the maximum hematoma area above the outer canthus-meatus line (OML) with the puncture point shown. A: brain CT. Extension lines from the center (C) of the hematoma vertically and horizontally outward to the frontal (F) scalp and temporal puncture $(P)$ point are represented by $C F$ and $C P$, respectively. Here, $C F$ is parallel to the median sagittal line (M), and CP is perpendicular to CF. $P$ is the puncture point. Puncture depth is the distance between C and P. B: a diagram of the puncture point on the body surface. Here, the distance from $F$ to $P$ is equal to the $C F$ line and parallel to the OML. The vertical length from the OML to $P$ on the body surface is equal to the height ( $\mathrm{mm}$ ) from the OML to the maximum hematoma slice on the $C T$ film. 


\section{Follow-up}

The primary outcome was death at 30 days after onset. Functional independence was assessed at 1 year using the Glasgow Outcome Scale [12] (GOS, scores range from 1 to 5 , score 1 indicating death, $\geq 4$ indicating functional independence, with lower scores indicating greater disability). The follow-up was completed by observer-blind neurologists via telephone or via an interview with the patient or their relative.

\section{Statistics}

Measurement data were expressed as “ $\bar{x} \pm s$ " when the data were distributed normally; otherwise, the data were expressed as " $\mathrm{M}\left(\mathrm{Q}_{1} \sim \mathrm{Q}_{3}\right)$ ". Baseline grouped measurement data that met the normality and homogeneity of variances criteria were analyzed using Student's $t$ test; otherwise, the Wilcoxon rank sum test was used. Chi- square or rank sum tests were used for categorical data. Because the outcome variable was ordinal, the Wilcoxon rank sum test was used to compare the difference between groups. Prognostic factors were analyzed using binary logistic regression (forward conditional method). For patients lost during follow-up, the patients' last observation was considered as the final outcome status to be included in the intention-to-treat analysis. All analyses were performed with SPSS 18.0. $P<0.05$ was considered to be a statistically significant difference.

\section{Results}

\section{General result}

Baseline data are shown in Table 1 and Figure 2. A total of 553 consecutive patients with spontaneous $\mathrm{ICH}$ in the basal ganglia were admitted. Of these patients, 355 were excluded (most for having $\mathrm{HV}<30 \mathrm{~mL}$, refusing the

Table 1 Clinic baseline characteristics

\begin{tabular}{|c|c|c|c|c|}
\hline \multirow[t]{2}{*}{ Characteristics } & \multirow{2}{*}{$\begin{array}{l}\text { All patients } \\
(\mathrm{n}=198)\end{array}$} & \multicolumn{2}{|c|}{ Groups } & \multirow[t]{2}{*}{$P$} \\
\hline & & $A(n=84)$ & $B(n=114)$ & \\
\hline Age, mean \pm SD (range) & $57.1 \pm 12.8(31-95)$ & $59.4 \pm 14.5(31-95)$ & $55.3 \pm 11.1(36-87)$ & $0.025^{a}$ \\
\hline$\leqq 60, \mathrm{n}(\%)$ & $49.5 \pm 6.7,130(65.7)$ & $48.4 \pm 7.2,45(53.6)$ & $50.0 \pm 6.4,85(74.6)$ & $0.209^{a}$ \\
\hline$>60, \mathrm{n}(\%)$ & $71.5 \pm 8.3,68(34.3)$ & $72.1 \pm 9.5,39(46.4)$ & $70.9 \pm 6.4,29(25.4)$ & $0.562^{a}$ \\
\hline Female/Male, n (\%) & $54(27.3) / 144(72.7)$ & $22(26.2) / 62(73.8)$ & $32(28.1) / 82(71.9)$ & 0.769 \\
\hline Diabetes, No/Yes, n (\%) & $127(64.1) / 71(35.9)$ & $60(71.4) / 24(28.6)$ & $67(58.8) / 47(41.2)$ & 0.066 \\
\hline Time from ictus to operation, $\mathrm{h}$ & & & & $0.123^{b}$ \\
\hline Median $(25 \%, 75 \%)$ & $7(5,9)$ & $7(6,10)$ & $6(5,9)$ & \\
\hline \multicolumn{5}{|l|}{$\mathrm{BP}(\mathrm{mm} \mathrm{Hg})$, mean $\pm \mathrm{SD}$} \\
\hline SBP & $188.1 \pm 26.4$ & $185.9 \pm 24.5$ & $189.8 \pm 27.7$ & $0.300^{a}$ \\
\hline DBP & $103.4 \pm 12.1$ & $102.1 \pm 11.1$ & $104.3 \pm 12.7$ & $0.108^{a}$ \\
\hline $\mathrm{GCS}$, mean $\pm \mathrm{SD}$ & $8.1 \pm 3.4$ & $8.6 \pm 3.6$ & $7.8 \pm 3.2$ & 0.082 \\
\hline $15-13, \mathrm{n}(\%)$ & $30(15.2)$ & $17(20.2)$ & $13(11.4)$ & $0.111^{b}$ \\
\hline $12-7, \mathrm{n}(\%)$ & $88(44.4)$ & $37(44.0)$ & $51(44.7)$ & \\
\hline $6-3, n(\%)$ & $80(40.4)$ & $30(35.7)$ & $50(43.9)$ & \\
\hline $\mathrm{NIHSS}$, mean $\pm \mathrm{SD}$ & $20.8 \pm 5.3$ & $20.2 \pm 5.5$ & $21.2 \pm 5.1$ & 0.194 \\
\hline$<15, \mathrm{n}(\%)$ & $32(16.2)$ & $17(20.2)$ & $15(13.2)$ & $0.163^{b}$ \\
\hline $15-20, \mathrm{n}(\%)$ & $50(25.3)$ & $22(26.2)$ & $28(24.6)$ & \\
\hline$>20, n(\%)$ & $116(58.6)$ & 45 (53.6) & $71(62.3)$ & \\
\hline $\mathrm{HV}$, mL (Range) & $56.7 \pm 23.0(30-144)$ & $53.7 \pm 23.4(30-144)$ & $58.9 \pm 22.5(30-128)$ & $0.119^{a}$ \\
\hline$\leqq 60 \mathrm{~mL}, \mathrm{n}(\%)$ & $43.12 \pm 8.9,131(66.2)$ & $41.9 \pm 8.9,61(72.6)$ & $44.2 \pm 8.8,70(61.4)$ & $0.142^{a}$ \\
\hline$>60$ mL, n (\%) & $83.2 \pm 18.6,67$ (33.8) & $85.0 \pm 21.1,23(27.4)$ & $82.2 \pm 17.3,44$ (38.6) & $0.560^{a}$ \\
\hline $\mathrm{IVH}, \mathrm{n}(\%)$, & & & & $0.219^{b}$ \\
\hline 0 & $64(32.3)$ & $30(35.7)$ & $34(29.8)$ & \\
\hline $1-4$ & $62(31.3)$ & $27(32.1)$ & $35(30.7)$ & \\
\hline $5-8$ & $36(18.2)$ & 15 (17.9) & $21(18.4)$ & \\
\hline $9-12$ & $36(18.2)$ & $12(14.3)$ & $24(21.1)$ & \\
\hline
\end{tabular}

$P$ values were calculated using the Chi-square, Student's $t\left({ }^{a}\right)$ or Wilcoxon rank sum tests $\left({ }^{b}\right)$. Groups: A, minimal invasive puncture and drainage; $B$, decompressive craniectomy; BP: blood pressure; SPB systolic blood pressure. DBP: diastolic blood pressure. GCS: Glasgow Coma Scale; NIHSS: National Institutes of Health Stroke Scale; HV: hematoma volume; IVH: intraventricular hemorrhage. 


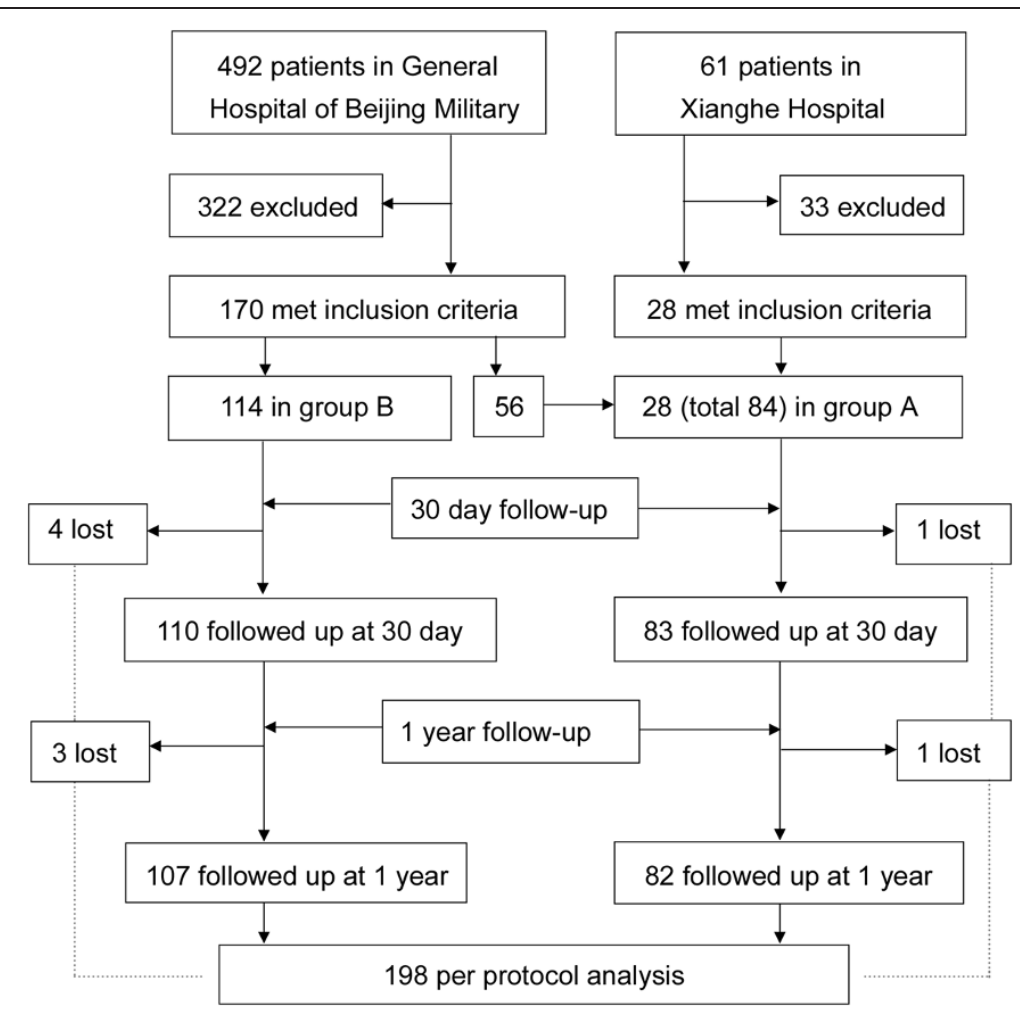

Figure 2 Trial profile. A total of 553 consecutive patients with ICH were admitted. Of these patients, 492 were admitted to the General Hospital of Beijing Military Region and 61 were admitted to the Xianghe Hospital. Based on the inclusion/exclusion criteria, 355 were excluded, and 198 were available according to the per protocol sample. Of those, 84 received minimally invasive puncture and drainage (group A), and 114 underwent decompressive craniectomy (group B) hematoma evacuations. Nine were lost during follow up at 30 days (1 and 4) and 1 year (1 and 3 in group A and group B, respectively). For those patients, their last observed data were used as their final results for intention-to-treat analysis.

operation, or having additional complications). Therefore, 198 patients were available for this study, including 9 cases that were lost during follow up. There were 84 cases in group A and 114 cases in group B, of which 2 and 7 were lost in each group, respectively, during follow up. The mean age was $57.1 \pm 12.8$ years (ranged 31-95), and the age of group A was older than group B $(59.4 \pm 14.5$ vs. $55.3 \pm 11.1$ years, $P=0.025)$. The mean $\mathrm{HV}$ was $56.7 \pm 23.0 \mathrm{~mL}$ (ranged $10-144 \mathrm{~mL}$ ). Patients with IVH accounted for $67.7 \%$ of the total patient population used. Except for age, there were no other significant differences between the two groups in their baseline data, including gender, blood pressure, initial GCS, NIHSS and the time from ictus to operation.

\section{Short-term outcome}

Table 2 shows the outcomes at 30 days after ictus. The cumulative total mortality was $32.3 \%(64 / 198)$, and the difference between group A (27.4\%) and group B (36.0\%) was not statistically significant $(\mathrm{OR}=1.490,95 \% \mathrm{CI}$ $0.807 \sim 2.751, P=0.203$ ). Additionally, no significant difference was observed between the two groups in the incidence of complications (RB, PI, RF and UGB) and their corresponding mortality. In addition, the incidence of secondary intracranial infection $(0$ and 2 in groups A and $B$, respectively) and required reoperation ( 0 and 2 in groups $\mathrm{A}$ and $\mathrm{B}$, respectively) was indistinguishable between the groups.

Further analysis using stratified variables indicated that for patients $\leqq 60$ years of age, NIHSS $<15$, or $\mathrm{HV} \leqq 60 \mathrm{~mL}$, the mortality of group A was significantly lower than that of group B. For patients with severe IVH, the mortality of group B was significantly lower than that of group A.

Univariate analysis showed that for patients with DM, GCS $\leqq 6$, NIHSS $>20, \mathrm{HV}>60 \mathrm{~mL}$ or IVH $>4$ or with complications (RB, RF or PI), the risk of mortality at 30 days after ictus was significantly increased.

Logistic regression analysis (Table 3) using the raw data revealed that after adjusting for age, sex and other factors, independent predictors of 30-day mortality included a lower baseline GCS and the presence of IVH combined with RB and RF. For a patient with RB or RF, the risk of death increased to more than 13 or 3 times, respectively.

The cumulative total favorable outcome $(\mathrm{GOS}>3)$ at 30 days post onset was $10.6 \%$ (21/198), i.e., only 21 of the 134 survivors were functionally independent. There was no significant difference between group A and 
Table 2 Mortality at $\mathbf{3 0}$ days

\begin{tabular}{|c|c|c|c|c|c|c|c|c|c|c|}
\hline & \multicolumn{3}{|c|}{ All Patients n (\%) } & \multicolumn{7}{|c|}{ Groups } \\
\hline & \multirow[b]{2}{*}{$\begin{array}{c}\text { Dead } \\
(\mathrm{GOS}=1)\end{array}$} & \multirow[b]{2}{*}{$\begin{array}{c}\text { Survival } \\
\text { GOS > 1) }\end{array}$} & \multirow[b]{2}{*}{$\mathbf{P}$} & \multicolumn{2}{|c|}{$A, n=84(\%)$} & \multirow[b]{2}{*}{ Total } & \multicolumn{2}{|c|}{$B, n=114(\%)$} & \multirow[b]{2}{*}{ Total } & \multirow[b]{2}{*}{$P$} \\
\hline & & & & $\begin{array}{c}\text { Dead } \\
(\mathrm{GOS}=1)\end{array}$ & $\begin{array}{c}\text { Survival } \\
\text { GOS > 1) }\end{array}$ & & $\begin{array}{c}\text { Dead } \\
(\mathrm{GOS}=1)\end{array}$ & $\begin{array}{c}\text { Survival } \\
(\mathrm{GOS}>1)\end{array}$ & & \\
\hline Total & $64(32.3)$ & $134(67.7)$ & & $23(27.4)$ & $61(72.6)$ & 84 & $41(36.0)$ & $73(64.0)$ & 114 & 0.203 \\
\hline Age & & & & & & & & & & 0.203 \\
\hline$\leqq 60$ & $42(32.3)$ & $88(67.7)$ & 0.995 & $9(20.0)$ & $36(80.0)$ & 45 & $33(38.8)$ & $52(61.2)$ & 85 & 0.030 \\
\hline$>60$ & $22(32.4)$ & $46(67.6)$ & & $14(35.9)$ & $25(64.1)$ & 39 & $8(27.6)$ & $21(72.4)$ & 29 & 0.472 \\
\hline Gender & & & & & & & & & & 0.203 \\
\hline Female & $14(25.9)$ & $40(74.1)$ & 0.240 & $4(18.2)$ & $18(81.8)$ & 22 & $10(31.3)$ & $22(68.8)$ & 32 & 0.286 \\
\hline Male & $50(34.7)$ & $94(65.3)$ & & 19 (30.6) & $43(69.4)$ & 62 & $31(37.8)$ & $51(62.2)$ & 82 & 0.373 \\
\hline Diabetes & & & & & & & & & & 0.203 \\
\hline No & $34(26.8)$ & $93(73.2)$ & 0.026 & $12(20.0)$ & $48(80.0)$ & 60 & $22(32.8)$ & $45(67.2)$ & 67 & 0.104 \\
\hline Yes & $30(42.3)$ & $41(57.7)$ & & $11(45.8)$ & $13(54.2)$ & 24 & $19(40.4)$ & $28(59.6)$ & 47 & 0.665 \\
\hline GCS & & & $<0.001$ & & & & & & & 0221 \\
\hline $15-13$ grade 1 & $2(6.7)$ & $28(93.3)$ & & $0(0.0)$ & $17(100.0)$ & 17 & $2(15.4)$ & $11(84.6)$ & 13 & 0.179 \\
\hline $12-7$ grade 2 & $21(23.9)$ & $67(76.1)$ & $0.059^{a}$ & $7(18.9)$ & 30 (81.1) & 37 & $14(27.5)$ & $37(72.5)$ & 51 & 0.357 \\
\hline $6-3$ grade 3 & $41(51.3)$ & $39(48.8)$ & $<0.001^{b}$ & $16(53.3)$ & $14(46.7)$ & 30 & $25(50.0)$ & $25(50.0)$ & 50 & 0.477 \\
\hline NIHSS & & & 0.001 & & & & & & & 0.221 \\
\hline$<15$ grade 1 & $5(15.6)$ & $27(84.4)$ & & $0(0.0)$ & $17(100)$ & 17 & $5(33.3)$ & $10(66.7)$ & 15 & 0.015 \\
\hline $15-20$ grade 2 & $9(18.0)$ & $41(82.0)$ & $1.000^{a}$ & $3(13.6)$ & $19(86.4)$ & 22 & $6(21.4)$ & $22(78.6)$ & 28 & 0.713 \\
\hline$>20$ grade 3 & $50(43.1)$ & $66(56.9)$ & $0.002^{b}$ & $20(44.4)$ & $25(55.6)$ & 45 & $30(42.3)$ & $41(55.7)$ & 71 & 0.817 \\
\hline $\mathrm{HV}, \mathrm{mL}$ & & & & & & & & & & 0.203 \\
\hline$\leqq 60$ & $29(22.1)$ & $102(77.9)$ & $<0.001$ & $8(13.1)$ & $53(86.9)$ & 61 & $21(30.0)$ & $49(70.0)$ & 70 & 0.021 \\
\hline$>60$ & $35(52.5)$ & $32(47.8)$ & & $15(65.2)$ & $8(34.8)$ & 23 & $20(45.5)$ & $24(54.5)$ & 44 & 0.127 \\
\hline IVH & & & $<0.001$ & & & & & & & 0.221 \\
\hline 0 & $12(18.8)$ & $52(81.3)$ & & $3(10.0)$ & $27(90.0)$ & 30 & $9(26.5)$ & $25(73.5)$ & 34 & 0.117 \\
\hline 1-4 grade 1 & $10(16.1)$ & $52(83.9)$ & $0.816^{c}$ & $3(11.1)$ & $24(88.9)$ & 27 & $7(20.0)$ & $28(80.0)$ & 35 & 0.491 \\
\hline $5-8$ grade 2 & $19(52.8)$ & 17 (47.2) & $<0.001^{a}$ & $6(40.0)$ & $9(60.0)$ & 15 & $13(61.9)$ & $8(38.1)$ & 21 & 0.201 \\
\hline $9-12$ grade 3 & $23(63.9)$ & $13(36.1)$ & $0.471^{b}$ & $11(91.7)$ & $1(8.3)$ & 12 & $12(50.0)$ & $12(50.0)$ & 24 & 0.025 \\
\hline \multicolumn{11}{|c|}{ Complications, n (\%) } \\
\hline $\mathrm{RB}$ & & & & & & & & & & 0.221 \\
\hline No & $57(30.2)$ & $132(69.8)$ & 0.006 & $22(26.5)$ & $61(73.5)$ & 83 & $35(33.0)$ & $71(67.0)$ & 106 & 0.334 \\
\hline Yes & $7(77.8)$ & $2(22.2)$ & & $1(100)$ & $0(0.0)$ & 1 & $6(75.0)$ & $2(25.0)$ & 8 & 1.000 \\
\hline RF & & & & & & & & & & 0.221 \\
\hline NO & $50(28.2)$ & $127(71.8)$ & 0.001 & $19(24.1)$ & $60(75.9)$ & 79 & 31 (31.6) & $67(68.4)$ & 98 & 0.267 \\
\hline Yes & $14(66.7)$ & $7(33.3)$ & & $4(80.0)$ & $1(20.0)$ & 5 & $10(62.5)$ & $6(37.5)$ & 16 & 0.624 \\
\hline $\mathrm{Pl}$ & & & & & & & & & & 0.203 \\
\hline No & $31(26.7)$ & $85(73.3)$ & 0.046 & $12(24.0)$ & $38(76.0)$ & 50 & $19(28.8)$ & $47(71.2)$ & 66 & 0.566 \\
\hline Yes & $33(40.2)$ & $49(59.8)$ & & $11(32.4)$ & $23(67.6)$ & 34 & $22(45.8)$ & $26(54.2)$ & 48 & 0.223 \\
\hline UGB & & & & & & & & & & 0.221 \\
\hline No & $56(30.6)$ & $127(69.4)$ & 0.087 & $19(24.7)$ & $58(75.3)$ & 77 & $37(34.9)$ & $69(65.1)$ & 106 & 0.139 \\
\hline Yes & $8(53.3)$ & $7(46.7)$ & & $4(57.1)$ & $3(42.9)$ & 7 & $4(50.0)$ & $4(50.0)$ & 8 & 1.000 \\
\hline
\end{tabular}

$P$ values were calculated using the Wilcoxon or Kruskal-Wallis rank sum tests. Groups: A, minimal invasive puncture and drainage; $B$, decompressive craniectomy; GOS: Glasgow Outcome Scale; BP: blood pressure; SPB systolic blood pressure. DBP: diastolic blood pressure. GCS: Glasgow Coma Scale; NIHSS: National Institutes of Health Stroke Scale; HV: hematoma volume; IVH: intraventricular hemorrhage; RB: rebleed; PI: pulmonary infection; RF: renal failure; UGB: upper gastrointestinal bleeding; ${ }^{a}$ grade 1 vs. grade $2 ;^{b}$ grade 2 vs. grade $3 ;{ }^{c} \mathrm{IVH} 0$ vs. IVH grade 1. 
group B $(11.9 \%$, vs. $11.4 \%, P=0.914$, detailed data not provided).

\section{Long-term outcome}

Table 4 shows that the cumulative total mortality at 1 year after ictus was $43.4 \%(86 / 198)$ and that the difference between group $\mathrm{A}$ and group $\mathrm{B}$ was not significant (36.1\% vs. $48.2 \%, P=0.112$ ).

Further analysis using stratified variables showed that for patients $\leqq 60$ years of age, NIHSS $<15, \mathrm{HV} \leqq 60 \mathrm{~mL}$, no IVH, or no UGB, the 1-year mortality of group A was significantly lower than that for group B. For patients with IVH scores of 9-12, the 1-year mortality of group B was obviously lower than that of group A. Other stratified variables showed no significant differences between groups.

Using univariate analysis, higher mortality was shown to be closely related with DM (53.5\%), initial GCS $\leqq 6$ (67.5\%), NIHSS > 20 (57.8\%), HV > $60 \mathrm{~mL}$ (67.2\%) and IVH $>4(75 \%)$ and also with any complication, RB (77.8\%), RF (85.7\%), PI (58.5\%) and UGB (73.3\%).

Using multivariate analysis (Table 5) on the raw data after being adjusted for other factors, age, GCS, HV, IVH, RB and RF were determined to be independent risk factors for fatality at 1 year: the higher the initial GCS score, the lower the risk of death at 1 year after onset. If a patient had RB or RF complications, the risk of death at 1 year was increased by 8 or 6 times, respectively.

The 1-year prognosis-based GOS showed favorable outcomes in $39.3 \%$ of the patients in group $\mathrm{A}$ and in $17.5 \%$ of patients in group B $(P=0.001$, Table 6$)$; therefore, the absolute difference in the favorable outcome between MIPD and DC was $21.8 \%$ (OR $=0.329,95 \%$ CI 0.171 to $0.631, P=0.001)$. Logistic regression analysis indicated that different treatments, age, GCS, HV, IVH and PI were all significant factors for favorable outcomes at 1 year (Table 7). Specifically, MIPD treatment, younger age, higher initial GCS, less HV and the absence of IVH/PI were associated with more favorable outcomes at 1 year after ictus.

Table 3 Binary logistic analyze of morality risk at 30-day of ictus

\begin{tabular}{lrrrrrrrr}
\hline $\begin{array}{l}\text { Clinical } \\
\text { factors }\end{array}$ & B & S.E. & Wald & df & Sig. & $\begin{array}{r}\text { Exp } \\
\text { (B) }\end{array}$ & \multicolumn{2}{c}{$\mathbf{9 5 \%}$ Cl } \\
\hline GCS & -0.162 & 0.065 & 6.156 & 1 & 0.013 & 0.850 & 0.748 & 0.967 \\
IVH & 0.194 & 0.049 & 15.818 & 1 & 0.000 & 1.214 & 1.103 & 1.335 \\
RB & 2.574 & 0.890 & 8.354 & 1 & 0.004 & 13.113 & 2.290 & 75.099 \\
RF & 1.227 & 0.566 & 4.706 & 1 & 0.030 & 3.410 & 1.126 & 10.331 \\
Constant & -3.184 & 0.587 & 29.451 & 1 & $<.001$ & 0.041 & & \\
\hline
\end{tabular}

Method: Forward conditional; Entry 0.05, Removal: 0.10, Classification cutoff: 0.5 . Dependent: outcome at 30 -day of ictus: $0=$ survival, $1=$ dead. IVH: intraventricular hemorrhage; RB: rebleed, $0=$ no, 1 = yes; RF: renal failure, $0=$ no, $1=$ yes. All covariates used were original data.

\section{Discussion}

The mass effect of a hematoma can lead to brain damage, such as intracranial hypertension or a cerebral hernia. Some evidence suggests that the mass effect caused by HV $(<60 \mathrm{~mL})$ is not the dominant injury mechanism; rather, excitotoxic substances released from the hematoma, such as elevated glutamate levels in the perihematomal region, may have an important impact on secondary cerebral injury [13]. Therefore, the effective removal of the hematoma at the acute phase is crucial for the effective treatment of $\mathrm{ICH}$ and would allow for reducing mortality and improving long-term quality of life.

Surgical removal of the bone flap is a classical technique for treating $\mathrm{ICH}$; it is characterized by good visibility, complete removal of the hematoma, easy hemostasia, and a reduction of resultant pressure. However, there are also some shortcomings associated with the procedure, such as general anesthesia, duration of the surgery, possible brain distortion, possible damage to the brain tissue around the hematoma by electrocoagulation, rebleeding, and a potential for a series of pathophysiological changes post operation (such as disturbance in water and electrolytes) that can result in the severe impairment of neurological functions and multiple complications.

Several published randomized trials show that there is no benefit from conventional surgery compared with conservative medical treatment; $[14,15]$ for severe cases, the mortality from DC is as high as $64.7 \%$, and elderly patients rarely survive [16]. The STICH trial [5] failed to demonstrate the assumed superiority of operative treatment over conservative management. The study included 1033 patients (between 19 and 93 years of age; HV between 4 and $210 \mathrm{~mL}$ ) from 83 participating centers in 27 countries. There was no significant difference in mortality or favorable outcomes between the two groups at 6 months post ictus. Although craniotomy may be helpful in treating patients with lobar clots within $1 \mathrm{~cm}$ of the surface that present with GCS > 9, patients in the STICH study with a deep hematoma or with GCS $<8$ tended to fare worse with surgical removal compared with medical management.

The recently completed randomized STICH II trial [6] included 601 patients from 78 centers in 27 countries with superficial lobar ICH, a mean age of 65 years, a mean HV of $37 \mathrm{~mL}$ (ranged 10-100 mL), and no IVH. The study further indicated that early surgery ( $99 \%$ craniotomy and $1 \%$ minimally invasive procedures to evacuate the hematomas within $12 \mathrm{~h}$ of ictus) had no significant difference in 6-month mortality (18\% and 24\%) and good outcome rates (41\% and $38 \%$ ), compared with conservative treatment.

The guidelines for the management of spontaneous ICH by the American Heart Association/American Stroke Association in 2010 [17] recommended that for patients presenting with lobar clots of $>30 \mathrm{~mL}$ and within $1 \mathrm{~cm}$ of the surface, the evacuation of supratentorial $\mathrm{ICH}$ by 
Table 4 Morality at 1 year after ICH onset

\begin{tabular}{|c|c|c|c|c|c|c|c|c|c|c|}
\hline & \multicolumn{3}{|c|}{ All patients n (\%) } & \multicolumn{7}{|c|}{ Groups } \\
\hline & \multirow[b]{2}{*}{ Dead } & \multirow[b]{2}{*}{ Alive } & \multirow[b]{2}{*}{$P$} & \multicolumn{2}{|c|}{$A(n=84)$} & \multirow[b]{2}{*}{ Total } & \multicolumn{2}{|c|}{$B(n=114)$} & \multirow[b]{2}{*}{ Total } & \multirow[b]{2}{*}{$P$} \\
\hline & & & & Dead & Alive & & Dead & Alive & & \\
\hline & $86(43.4)$ & $112(56.6)$ & & $31(36.1)$ & $53(63.9)$ & 84 & $55(48.2)$ & $59(51.8)$ & 114 & 0.112 \\
\hline Age & & & & & & & & & & 0.112 \\
\hline$\leqq 60$ & $50(38.5)$ & $80(61.5)$ & 0.052 & $11(24.4)$ & $34(75.6)$ & 45 & $39(45.9)$ & $46(51.4)$ & 85 & 0.017 \\
\hline$>60$ & $36(52.9)$ & $32(47.1)$ & & $20(51.3)$ & $19(48.7)$ & 39 & $16(55.2)$ & $19(48.7)$ & 39 & 0.752 \\
\hline Gender & & & & & & & & & & 0.112 \\
\hline Female & $22(40.7)$ & $32(59.3)$ & 0.640 & $9(40.9)$ & $13(59.1)$ & 22 & $13(40.6)$ & $19(59.4)$ & 32 & 0.983 \\
\hline Male & $64(44.4)$ & 80 (55.6) & & $22(35.5)$ & $40(64.5)$ & 62 & $42(51.2)$ & $40(48.8)$ & 82 & 0.061 \\
\hline Diabetes & & & & & & & & & & 0.112 \\
\hline No & $48(37.8)$ & 79 (62.2) & 0.033 & $18(30.0)$ & $42(70.0)$ & 60 & $30(44.8)$ & $37(55.2)$ & 67 & 0.088 \\
\hline Yes & $38(53.5)$ & $33(46.5)$ & & $13(54.2)$ & $11(45.8)$ & 24 & $25(53.2)$ & $22(46.8)$ & 47 & 0.938 \\
\hline GCS & & & $<0.001$ & & & & & & & 0.147 \\
\hline $15-13$ grade 1 & $3(10.0)$ & $27(90.0)$ & & $0(0.0)$ & $17(100.0)$ & 17 & $3(23.1)$ & $10(76.9)$ & 13 & 0.070 \\
\hline $12-7$ grade 2 & $29(33.0)$ & $59(67.0)$ & $0.017^{a}$ & $8(21.6)$ & $29(78.4)$ & 37 & $21(41.2)$ & $30(58.8)$ & 51 & 0.055 \\
\hline $6-3$ grade 3 & $54(67.5)$ & $26(32.5)$ & $<0.001^{b}$ & $23(76.7)$ & $7(23.3)$ & 30 & $31(62.0)$ & $19(38.0)$ & 50 & 0.178 \\
\hline $\mathrm{NIHSS}$ & & & $<0.001$ & & & & & & & 0.147 \\
\hline$<15$ grade 1 & 5 (15.6) & 27 (84.4) & & $0(0.0)$ & $17(100.0)$ & 17 & $5(33.3)$ & $10(66.7)$ & 15 & 0.015 \\
\hline 15 -20 grade 2 & $14(28.0)$ & $36(72.0)$ & $0.284^{a}$ & $4(18.2)$ & $18(81.8)$ & 22 & $10(35.7)$ & $18(64.3)$ & 28 & 0.175 \\
\hline$>20$ grade 3 & $67(57.8)$ & $49(42.2)$ & $<0.001^{b}$ & $27(60.0)$ & $18(40.0)$ & 45 & $40(56.3)$ & $31(43.7)$ & 71 & 0.698 \\
\hline $\mathrm{HV}, \mathrm{mL}$ & & & & & & & & & & 0.112 \\
\hline$\leqq 60$ & 41 (31.3) & 90 (68.7) & $<0.001$ & $13(21.3)$ & 48 (78.7) & 61 & $28(40.0)$ & $42(60.0)$ & 70 & 0.022 \\
\hline$>60$ & $45(67.2)$ & $22(32.8)$ & & $18(78.3)$ & $5(21.7)$ & 23 & $27(61.4)$ & 17 (38.6) & 44 & 0.165 \\
\hline IVH & & & $<0.001$ & & & & & & & 0.147 \\
\hline 0 & $16(25.0)$ & $48(75.0)$ & $0.918^{c}$ & $3(10.0)$ & $27(90.0)$ & 30 & $13(38.2)$ & $21(61.8)$ & 34 & 0.010 \\
\hline $1-4$ & $16(25.8)$ & $46(74.2)$ & & $5(18.5)$ & $22(81.5)$ & 27 & $11(31.4)$ & 24 (68.6) & 35 & 0.253 \\
\hline $5-8$ & $27(75.0)$ & $9(25.0)$ & $<0.001^{a}$ & $11(73.3)$ & $4(26.7)$ & 15 & $16(76.2)$ & $5(23.8)$ & 21 & 1.000 \\
\hline $9-12$ & $27(75.0)$ & $9(25.0)$ & $1.000^{b}$ & $12(100.0)$ & $0(0.0)$ & 12 & $15(62.5)$ & $9(37.5)$ & 24 & 0.036 \\
\hline \multicolumn{11}{|c|}{ Complications, n (\%) } \\
\hline $\mathrm{RB}$ & & & & & & & & & & 0.147 \\
\hline No & $79(41.8)$ & $110(58.2)$ & 0.042 & $30(36.1)$ & $53(63.9)$ & 83 & $49(46.2)$ & $57(53.8)$ & 106 & 0.164 \\
\hline Yes & 7 (77.8) & $2(22.2)$ & & $1(100.0)$ & 0 & 1 & $6(75.0)$ & $2(25.0)$ & 8 & 1.000 \\
\hline $\mathrm{RF}$ & & & & & & & & & & 0.147 \\
\hline NO & $68(38.4)$ & $109(61.6)$ & $<0.001$ & $26(32.9)$ & $53(67.1)$ & 79 & $42(42.9)$ & $56(57.1)$ & 98 & 0.177 \\
\hline Yes & $18(85.7)$ & $3(14.3)$ & & $5(100.0)$ & 0 & 5 & $13(81.3)$ & $3(18.8)$ & 16 & 0.549 \\
\hline $\mathrm{Pl}$ & & & & & & & & & & 0.147 \\
\hline No & $38(32.8)$ & $78(67.2)$ & $<0.001$ & $13(26.0)$ & $37(74.0)$ & 50 & $25(37.9)$ & $41(62.1)$ & 66 & 0.179 \\
\hline Yes & $48(58.5)$ & $34(41.5)$ & & $18(52.9)$ & $16(47.1)$ & 34 & $30(62.5)$ & $18(37.5)$ & 48 & 0.496 \\
\hline UGB & & & & & & & & & & 0.147 \\
\hline No & $75(41.0)$ & $108(59.0)$ & 0.027 & $25(32.5)$ & $52(67.5)$ & 77 & $50(47.2)$ & $56(52.8)$ & 106 & 0.046 \\
\hline Yes & $11(73.3)$ & $4(26.7)$ & & $6(85.7)$ & $1(14.3)$ & 7 & $5(62.5)$ & $3(37.5)$ & 8 & 0.569 \\
\hline
\end{tabular}

$P$ values were calculated using the Wilcoxon or Kruskal-Wallis rank sum tests. Groups: A, minimal invasive puncture and drainage; $B$, decompressive craniectomy; BP: blood pressure; SPB systolic blood pressure. DBP: diastolic blood pressure. GCS: Glasgow Coma Scale; NIHSS: National Institutes of Health Stroke Scale; HV: hematoma volume; IVH: intraventricular hemorrhage; RB: rebleed; PI: pulmonary infection; RF: renal failure; UGB: upper gastrointestinal bleeding; ${ }^{a}$ grade 1 vs. grade $2{ }^{b}$ grade 2 vs. grade $3{ }^{c} \mathrm{IVH} 0$ vs. IVH grade 1. 


\begin{tabular}{|c|c|c|c|c|c|c|c|c|}
\hline \multirow{2}{*}{$\begin{array}{l}\text { Clinical } \\
\text { factors }\end{array}$} & \multirow[t]{2}{*}{ B } & \multirow[t]{2}{*}{ S.E. } & \multirow[t]{2}{*}{ Wald } & \multirow[t]{2}{*}{ df } & \multirow[t]{2}{*}{ Sig. } & \multirow[t]{2}{*}{$\operatorname{Exp}(B)$} & \multicolumn{2}{|c|}{$95 \% \mathrm{Cl}$} \\
\hline & & & & & & & Lower & Upper \\
\hline Age & 0.029 & 0.014 & 4.185 & 1 & 0.041 & 1.030 & 1.001 & 1.059 \\
\hline GCS & -0.172 & 0.066 & 6.782 & 1 & 0.009 & 0.842 & 0.739 & 0.958 \\
\hline HV & 0.021 & 0.010 & 4.220 & 1 & 0.040 & 1.021 & 1.001 & 1.042 \\
\hline $\mathrm{IVH}$ & 0.182 & 0.051 & 12.588 & 1 & 0.000 & 1.200 & 1.085 & 1.327 \\
\hline $\mathrm{RB}$ & 2.170 & 0.935 & 5.389 & 1 & 0.020 & 8.758 & 1.402 & 54.706 \\
\hline RF & 1.881 & 0.730 & 6.636 & 1 & 0.010 & 6.561 & 1.568 & 27.448 \\
\hline Constant & -2.752 & 1.172 & 5.512 & 1 & 0.019 & 0.064 & & \\
\hline
\end{tabular}

Method: Forward conditional; Entry 0.05, Removal: 0.10, Classification cutoff: 0.5. Dependent: outcome at 1-year of ictus: $0=$ survival, 1 = dead. GCS: Glasgow Coma Scale; HV: hemorrhagic volume; IVH: intraventricular hemorrhage; RB: rebleed, $0=$ no, 1 = yes; RF: renal failure, $0=$ no, $1=$ yes; All covariates used were original data.

standard craniotomy may be considered; however, for most patients with supratentorial deep ICH, the usefulness of DC is uncertain. An ideal technique for ICH evacuation would be one that minimizes brain manipulation and that could also be performed under minimal anesthesia, preferably at the bedside. The 2007 consensus conference sponsored by the U.S. National Institutes of Health used favorable results of a number of studies and case reports to note that minimally invasive techniques to evacuate clots appear to be a promising area that warrants further investigation [18].

MIPD has become more attractive than DC for treating ICH for the following reasons. First, the YL-1 type puncture needle is designed with a $3.2-\mathrm{mm}$ outer diameter for minimizing the potential exacerbation of secondary brain trauma by avoiding the need for a craniectomy and a brain retraction. Second, the YL-1 type puncture needle has a built-in aiguille for perforating through the skull and dura and has an additional washing needle to replace the aiguille after drilling is complete. For flushing the hematoma, the washing liquid is pushed by a syringe and is ejected from the distal end in all directions, helping to liquefy, dissolve and drain the coagulated clot. Third, the operation can be accomplished at the bedside under local anesthesia in approximately half an hour. For these reasons, it has been widely adopted in China.

However, there are few studies that compare the efficacies of MIPD and DC for deep ICH. The randomized trial by Zhou et al. [19] showed that compared with DC, MIPD did not decrease short-term mortality but significantly improved long-term outcomes.

In the present study, the 30-day mortality rates of groups A and B were similar (27.4\% vs. $36.0 \%, P=0.203$ ); however, good outcomes at 1 year $(39.3 \%$ vs. $17.5 \%$ $P<0.001$ ) were significantly higher for the MIPD group. Although our MIPD results were similar to those in the STICH II study, all of the patients in
STICH II had superficial lobar hemorrhages, absent of $\mathrm{IVH}$, and more than half were fully conscious, whereas all of our patients had hemorrhages at supratentorial deep locations, $67.7 \%$ presented with IVH, and $84.8 \%$ had a GCS score $\leqq 12$. The remarkable difference in the favorable long-term outcomes between STICH II and our study suggests that MIPD may be more helpful in improving the neurologic functional outcome of patients with $\mathrm{ICH}$.

Logistic regression analysis revealed that the risk factors for 30-day mortality were GCS, IVH, RB and RF (Table 3). Different treatments, age, GCS, HV, IVH and PI were important factors that impacted the favorable outcomes at 1 year (Table 7 ).

Age was correlated with $\mathrm{ICH}$ prognosis: the older the patients, the higher their risk of death (Table 5); the younger, the greater the likelihood of a favorable outcome (Table 7). For patients $\leqq 60$ years of age, both the 30-day and 1-year mortalities of group A were significantly lower, and the 1-year good outcomes were significantly higher than those for group B. For patients older than 60 years of age, there was no noticeable difference in short- or long-term outcomes between the groups. This result implies that MIPD treatment can improve the treatment prognosis for younger patients with $\mathrm{ICH}$.

GCS is the most common scoring system used to describe the level of consciousness and the severity of disability of a patient with brain injury. It correlates well with outcomes following severe brain injury [20]. Our data showed that the 30-day mortality of patients with initial GCS scores of $15-13,12-7$ and $6-3$, was $6.7 \%, 23.9 \%$ and $51.3 \%$, respectively; the 1 -year mortality was $10.0 \%, 33.0 \%$ and $67.5 \%$ and the 1 -year favorable outcome was $53.3 \%, 37.5 \%$ and $5.0 \%$, respectively. The 1 -year good outcome rates for patients with mild to moderate disturbances of consciousness in group A were more than twice as high as those in group B $(70.6 \%$ vs. $30.8 \%$, $P=0.033$; $51.4 \%$ vs. $27.5 \%, P=0.023)$. This result indicates that MIPD significantly increased the long-term good outcome rate for patients with mild to moderately impaired consciousness.

HV is an important prognosis-associated factor. For patients with $\mathrm{HV}>60 \mathrm{~mL}$, the mortality rates at 30 days (52.5\%) and 1 year $(67.2 \%)$ post ictus were two times higher than those with $\mathrm{HV}<60 \mathrm{~mL}(22.1 \%$ and $31.3 \%$, respectively, all $P<0.001$ ), and there was no significant difference between groups $\mathrm{A}$ and $\mathrm{B}$. By contrast, for patients with $\mathrm{HV} \leqq 60 \mathrm{~mL}$, the mortality in group A at 30 days (13.1\%) and 1 year (21.3\%) was significantly lower than those for group B $(30.0 \%$ and $40.0 \%$, respectively, all $P<0.05)$. The favorable outcome rate at 1 year was significantly higher in group A than that in group B (52.5\% vs. $27.1 \%, P=0.003)$. These results suggest that patients with $\mathrm{HV} \leqq 60 \mathrm{~mL}$ may benefit from the treatment 
Table 6 Comparison of good outcome at 1 year

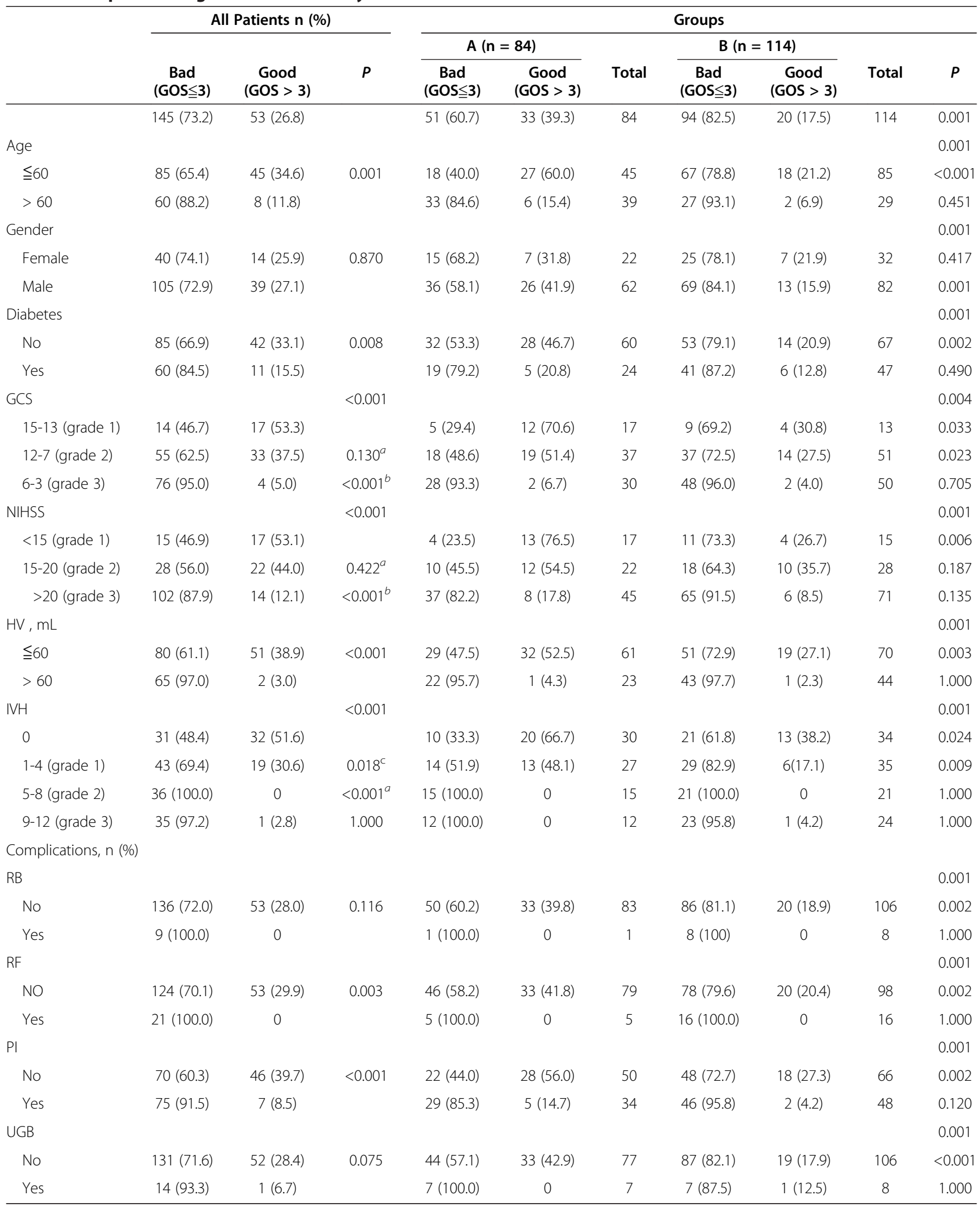

$P$ values were calculated using the Wilcoxon or Kruskal-Wallis rank sum tests. Groups: A, minimal invasive puncture and drainage; $B$, decompressive craniectomy; GOS: Glasgow Outcome Scale; BP: blood pressure; SPB systolic blood pressure. DBP: diastolic blood pressure. GCS: Glasgow Coma Scale; NIHSS: National Institutes of Health Stroke Scale; HV: hematoma volume; IVH: intraventricular hemorrhage; RB: rebleed; PI: pulmonary infection; RF: renal failure; UGB: upper gastrointestinal bleeding; ${ }^{a}$ grade 1 vs. grade $2 ;^{b}$ grade 2 vs. grade $3 ;{ }^{c}$ IVH 0 vs. IVH grade 1. 


\begin{tabular}{|c|c|c|c|c|c|c|c|c|}
\hline \multirow[t]{2}{*}{ Variables } & \multirow[t]{2}{*}{ B } & \multirow[t]{2}{*}{ S.E. } & \multirow[t]{2}{*}{ Wald } & \multirow[t]{2}{*}{ df } & \multirow[t]{2}{*}{ Sig. } & \multirow[t]{2}{*}{$\operatorname{Exp}(B)$} & \multicolumn{2}{|c|}{$95 \% \mathrm{Cl}$} \\
\hline & & & & & & & Lower & Upper \\
\hline Group & -1.274 & 0.504 & 6.381 & 1 & 0.012 & 0.280 & 0.104 & 0.752 \\
\hline Age & -1.538 & 0.581 & 7.004 & 1 & 0.008 & 0.215 & 0.069 & 0.671 \\
\hline GCS & 0.171 & 0.082 & 4.352 & 1 & 0.037 & 1.187 & 1.010 & 1.395 \\
\hline HV & -0.059 & 0.021 & 8.065 & 1 & 0.005 & 0.943 & 0.906 & 0.982 \\
\hline IVH & -0.423 & 0.132 & 10.268 & 1 & 0.001 & 0.655 & 0.506 & 0.849 \\
\hline 이 & -1.556 & 0.554 & 7.900 & 1 & 0.005 & 0.211 & 0.071 & 0.624 \\
\hline Constant & 5.503 & 1.717 & 10.276 & 1 & 0.001 & 245.452 & & \\
\hline
\end{tabular}

Method: Forward conditional; Entry 0.05, Removal: 0.10, Classification cutoff 0.5. Dependent: outcome at 1 -year of ictus: $0=$ bad, $1=$ favorable (Glasgow Outcome Scale score $\geqq 3$ ); Group: 1 = minimal invasive puncture and drainage, 2 = decompressive craniectomy; GCS: Glasgow Coma Scale; HV: hemorrhagic volume; IVH: intraventricular hemorrhage; Pl: pulmonary infection, $0=$ no, $1=$ yes. All covariates used were original data except for Age $(1, \leqq 60$ years; $2,>60$ years).

of MIPD more than DC, compared with those with $\mathrm{HV}>60 \mathrm{~mL}$, in terms of decreasing mortality and increasing neurologic functional independence.

IVH secondary to ICH is a powerful and independent risk factor for poor prognosis, particularly severe IVH. The mortality at 30 days can be as high as $91.7 \%$ [1]. The high mortality of IVH is related to the volume of IVH, obstruction of cerebrospinal fluid circulation, [21] and toxic effects of ventricular blood clots, which could lead to secondary cerebral vasospasms and acute obstructive hydrocephalus, especially when the third and fourth ventricles are involved [22].

In the present study, the incidence of IVH was $67.7 \%$ $(134 / 198)$. Of those, 36 cases were severe, and the mortality in group A and group B at 30 days were 91.7\% and $50.0 \%(P=0.025)$, respectively, and $100 \%$ and 62.5\% $(P=0.036)$, respectively, at 1 year. DC treatment can be advantageous for reducing mortality in patients with severe IVH. This benefit can be attributed to the more thorough evacuation of the hematoma and more adequate ventricular drainage, which more effectively reduces the obstruction of the circulation of the cerebrospinal fluid. However, the favorable outcome in patients with severe IVH at 1 year was similar between the two groups.

$\mathrm{RB}$ is also an independent risk factor for mortality (Table 3, Table 5), with an incidence of 4.5\% (9/198, 1 case in group A and 8 cases in group B). Among these, only 2 patients in group B survived at 1-year after ictus but developed serious disabilities. RF is another potentially fatal complication and had an incidence of $10.6 \%$ (5 cases in group A and 16 cases in group B). All of the RF cases in group A and 13 of the RF cases in group B died at 1 year post onset; the remaining 3 cases in group B survived with dependency. PI and UGB are also common complications of ICH, with incidences of $41.4 \%$ and $7.6 \%$, respectively.

The morbidity rate of the above complications was not significantly different between the two groups. However, in patients without these complications, the long-term good outcome rate was significantly higher in group A than that in group B (all $P<0.01$, Table 6). This result suggests that DC is disadvantageous for neurological function recovery when performed in patients with these complications and that the active prevention and treatment of these complications is essential for improving the prognosis of patients with $\mathrm{ICH}$.

One of the key points of MIPD hematoma evacuation is to ensure that the coagulated clot is completely liquefied, as most acute hematomas are solid or semisolid and may therefore block the drainage system. Thrombolytics have been used to dissolve coagulated clots to make them more amenable to be aspirated or drained.

Trials of minimally invasive surgeries in combination with recombinant tissue plasminogen activator (rtPA) for ICH evacuation show that rtPA, administered both intraventricularly and intracerebrally, are safe and effective for promoting clot dissolution [21,23]. However, due to its cost, rtPA is not readily available for clot thrombolysis in ICH patients in China. The patients in group A received urokinase injections into the hematoma, with only one case (1.2\%) developing RB. Patients in group B did not receive urokinase injections, and 8 cases (7.0\%) developed RB, implying that RB may not be associated with urokinase.

\section{Conclusion}

Our results demonstrate that for patients with hypertensive spontaneous ICH ( $\mathrm{HV} \geqq 30 \mathrm{~mL}$ in the basal ganglia), MIPD may be more effective than DC for achieving a higher rate of functional independence at 1 year as well as a lower mortality rate in some patients $\leqq 60$ years of age, with an NIHSS score $<15$ or $\mathrm{HV} \leqq 60 \mathrm{~mL}$. For patient with $\mathrm{HV}>60 \mathrm{~mL}$, deep coma or severe IVH, the outcomes of the two therapies were similar. Further randomized control trials are needed to assess the benefits of MIPD for hypertensive spontaneous deep ICH.

\section{Abbreviations \\ BP: Blood pressure; Cl: Confidence interval; DBP: Diastolic blood pressure; DC: Decompressive craniectomy; DM: Diabetes mellitus; GCS: Glasgow coma scale; ICH: Intracranial hemorrhage; HV: Hematoma volume; IVH: Intraventricular hemorrhage; MIPD: Minimally invasive puncture and drainage; NIHSS: National Institutes of Health Stroke Scale; OR: Odds ratio; PI: Pulmonary infection; RB: Rebleed; RF: Renal failure; rtPA: Recombinant tissue plasminogen activator; SPB: Systolic blood pressure; UGB: Upper gastrointestinal bleeding.}

\section{Competing interests}

The authors declare that they have no competing interests.

\section{Authors' contributions}

GW, SL, WZ and WY designed the trial, performed the statistical analysis and drafted the manuscript. GW performed the minimal invasive puncture and drainage. WZ obtained the funding and revised the manuscript. $\mathrm{YH}$ and $\mathrm{YL}$ 
completed patient's follow-up. JQ, YL and PL performed patient's decompressive craniectomy. WR, ZR, JZ, YD and JP assisted minimal invasive puncture were in charge of patient management. All authors had full access to all the data in the study and had responsibility for the integrity of the data and the accuracy of the data analysis. All authors read and approved the final manuscript.

\section{Acknowledgements}

This work was supported by grant from the National Natural Science Foundation of China (No. 81070948).

\section{Author details}

'Department of Neurology, General Hospital of Beijing Command, Beijing 100700, China. ${ }^{2}$ Department of Neurology, Xianghe Hospital of Traditional Chinese Medicine, Xianghe County, Hebei Province 654000, China. ${ }^{3}$ Department of Neurosurgery, General Hospital of Beijing Command, Beijing 100700, China.

Received: 5 May 2014 Accepted: 5 May 2014

Published: 1 June 2014

\section{References}

1. Muengtaweepongsa S, Seamhan B: Predicting mortality rate with $\mathrm{ICH}$ score in Thai intracerebral hemorrhage patients. Neurol Asia 2013, 18(2):131-135

2. Fogelholm R, Murros $K$, Rissanen A, Avikainen S: Long term survival after primary intracerebral haemorrhage: a retrospective population based study. J Neurol Neurosurg Psychiatry 2005, 76(11):1534.

3. Russell MW, Boulanger L, Joshi AV, Neumann PJ, Menzin J: The economic burden of intracerebral hemorrhage: evidence from managed care. Manag Care Interface 2006, 19(6):24-28.

4. Vespa P, McArthur D, Miller C, O'Phelan K, Frazee J, Kidwell C, Saver J, Starkman S, Martin N: Frameless stereotactic aspiration and thrombolysis of deep intracerebral hemorrhage is associated with reduction of hemorrhage volume and neurological improvement. Neurocrit Care 2005, 2(3):274-281.

5. Mendelow AD, Gregson BA, Fernandes HM, Murray GD, Teasdale GM, Hope DT, Karimi A, Shaw MD, Barer DH: STICH investigators. Early surgery versus initial conservative treatment in patients with spontaneous supratentorial intracerebral haematomas in the International Surgical Trial in Intracerebral Haemorrhage (STICH): a randomised trial. Lancet 2005, 365(9457):387-397.

6. Mendelow AD, Gregson BA, Rowan EN, Murray GD, Gholkar A, Mitchell PM, STICH II: Investigators. Early surgery versus initial conservative treatment in patients with spontaneous supratentorial lobar intracerebral haematomas (STICH II): a randomised trial. Lancet 2013, 382(9890):397-408.

7. Miller CM, Vespa P, Saver JL, Kidwell CS, Carmichael ST, Alger J, Frazee J, Starkman S, Liebeskind D, Nenov V, Elashoff R, Martin N: Image-guided endoscopic evacuation of spontaneous intracerebral hemorrhage. Surg Neurol 2008, 69(5):441-446.

8. Nishihara T, Morita A, Teraoka A, Kirino T: Endoscopy-guided removal of spontaneous intracerebral hemorrhage: comparison with computer tomography-guided stereotactic evacuation. Childs Nerv Syst 2007, 23(6):677-683

9. Cho DY, Chen CC, Lee WY, Lee HC, Ho LH: A new Modified Intracerebral Hemorrhage score for treatment decisions in basal ganglia hemorrhage-a randomized trial. Crit Care Med 2008, 36(7):2151-2156.

10. Broderick JP, Brott TG, Duldner JE, Tomsick T, Huster G: Volume of intracerebral hemorrhage: a powerful and easy-to-use predictor of 30-day mortality. Stroke 1993, 24(7):987-993.

11. Graeb DA, Robertson WD, Lapointe JS, Nugent RA, Harrison PB: Computed tomographic diagnosis of intraventricular hemorrhage. Etiology and prognosis. Radiology 1982, 143(1):91-96

12. Kosty J, Macyszyn L, Lai K, McCroskery J, Park HR, Stein SC: Relating quality of life to Glasgow outcome scale health states. J Neurotrauma 2012. 29(7):1322-1327.

13. Miller CM, Vespa PM, McArthur DL, Hirt D, Etchepare M: Frameless stereotactic aspiration and thrombolysis of deep intracerebral hemorrhage is associated with reduced levels of extracellular cerebral glutamate and unchanged lactate pyruvate ratios. Neurocrit Care 2007, 6(1):22-29.
14. Sykora M, Diedler J, Jüttler E, Steiner T, Zweckberger K, Hacke W, Unterberg A: Intensive care management of acute stroke: surgical treatment. Int J Stroke 2010, 5(3):170-177.

15. Elliott J, Smith M: The acute management of intracerebral hemorrhage: a clinical review. Anesth Analg 2010, 110(5):1419-1427.

16. Djurović BM, Tasić GM, Jovanović VT, Nikolić IM, Krunić-Protić RV, Radulović $D V$, Joković MB, llić RV: Neurosurgical treatment of spontaneous and traumatic intracerebral hematomas. Acta Chir lugos/ 2008, 55(2):123-127.

17. Morgenstern LB, Hemphill JC 3rd, Anderson C, Becker K, Broderick JP, Connolly ES Jr, Greenberg SM, Huang JN, MacDonald RL, Messé SR, Mitchell PH, Selim M, Tamargo RJ: Guidelines for the management of spontaneous intracerebral hemorrhage: a guideline for healthcare professionals from the American Heart Association/American Stroke Association. Stroke 2010, 41(9):2108-2129.

18. Broderick J, Connolly S, Feldmann E, Hanley D, Kase C, Krieger D, Mayberg M, Morgenstern L, Ogilvy CS, Vespa P, Zuccarello M, American Heart Association; American Stroke Association Stroke Council; High Blood Pressure Research Council; Ouality of Care and Outcomes in Research Interdisciplinary Working Group: Guidelines for the management of spontaneous intracerebral hemorrhage in adults: 2007 update: a guideline from the American Heart Association/American Stroke Association Stroke Council, High Blood Pressure Research Council, and the Quality of Care and Outcomes in Research Interdisciplinary Working Group. Stroke 2007, 38(6):2001-2023.

19. Zhou H, Zhang Y, Liu L, Huang Y, Tang Y, Su J, Hua W, Han X, Xue J, Dong Q: Minimally invasive stereotactic puncture and thrombolysis therapy improves long-term outcome after acute intracerebral hemorrhage. J Neurol 2011, 258(4):661-669.

20. Parry-Jones AR, Abid KA, di Napoli M, Smith CJ, Vail A, Patel HC, King AT, Tyrrell PJ: Accuracy and clinical usefulness of intracerebral hemorrhage grading scores: a direct comparison in a UK population. Stroke 2013, 44(7):1840-1845.

21. Hallevi H, Albright KC, Aronowski J, Barreto AD, Martin-Schild S, Khaja AM, Gonzales NR, Illoh K, Noser EA, Grotta JC: Intraventricular hemorrhage: anatomic relationships and clinical implications. Neurology 2008, 70(11):848-852.

22. Pantazis G, Tsitsopoulos P, Mihas C, Katsiva V, Stavrianos V, Zymaris S: Early surgical treatment vs conservative management for spontaneous supratentorial intracerebral hematomas: a prospective randomized study. Surg Neurol 2006, 66(5):492-501.

23. Morgan T, Zuccarello M, Narayan R, Keyl P, Lane K, Hanley D: Preliminary findings of the minimally-invasive surgery plus rtPA for intracerebral hemorrhage evacuation (MISTIE) clinical trial. Acta Neurochir Supp/ 2008, 105:147-151.

doi:10.1186/2054-9369-1-10

Cite this article as: Wang et al:: Can minimally invasive puncture and drainage for hypertensive spontaneous Basal Ganglia intracerebral hemorrhage improve patient outcome: a prospective non-randomized comparative study. Military Medical Research 2014 1:10.

\section{Submit your next manuscript to BioMed Central and take full advantage of:}

- Convenient online submission

- Thorough peer review

- No space constraints or color figure charges

- Immediate publication on acceptance

- Inclusion in PubMed, CAS, Scopus and Google Scholar

- Research which is freely available for redistribution 